\title{
Mechanical and Microstructural Properties of Fly Ash Based Geopolymers
}

\author{
E. Arioz, Ö. Arioz, and Ö. M. Koçkar
}

\begin{abstract}
Geopolymers are new types of materials which can be synthesized by various natural materials or by-products as source material. Fly ash is a type of by-product can be used in the synthesis. Source materials are activated by alkaline solutions and silicate solutions. In this experimental study, fly ash was used for geopolymerisation. By this way, most generated by-product was converted to valuable product. As an activator solution, $4 \mathrm{M}$ sodium hydroxide and sodium silicate were used. Alkaline solution was selected in low molarity because of the corrosive effect of hydroxide solution. The geopolymer pastes cured at $120^{\circ} \mathrm{C}$ for $6 \mathrm{~h}, 15 \mathrm{~h}$ and 24 hours. X-ray Diffraction Spectroscopy and Scanning Electron Microscopy techniques were used to investigate the structure of the samples. As a result of analysis, geopolymeric structure was obtained by this synthesis conditions. It was found that the higher compressive strength values can be obtained with higher molarities if desired for applications like building materials. Also some fillers may be added to increase the compressive strength values. Test results have also revealed that the compressive strengths increased with increasing curing duration.
\end{abstract}

Index Terms-Geopolymer, activation, mechanical properties, microstructural properties.

\section{INTRODUCTION}

Each year, more than 100 million tons of coal ashes and desulphurization products which called coal combustion products (CCP) are produced throughout the European Union. The utilization of CCPs results in economic and environmental benefits like saving of energy and reduction in emissions of pollutants and $\mathrm{CO}_{2}$ emissions. [1]. CCPs are used in many applications due to their physical and chemical properties. The main applications are cement and concrete technology and in the production of lightweight aggregates [1], [2].

Fly ash is a fine grained dust consisted of melted vitreous particles of spherical shape [1]. The very large quantities are generated from coal-combustion in power plants [3]. American Coal Ash Association declared that 71, 7 million tons of fly ash was produced but only 31 million was used in several applications [2]. The rest is disposed in landfills and storage lagoons [4].

Fly is classified as pozzolans which form cementitious products at ambient temperatures [5]. Fly ash contains

Manscript received July 12, 2013; revised September 12, 2013.

E. Arioz and Ö. M. Koçkar are with the Department of Chemical Engineering, Faculty of Engineering and Architecture, Anadolu University, Eskișehir, Turkey (e-mail: mkockar@anadolu.edu.tr).

Ö. Arioz is with the Department of Civil Engineering, Faculty of Engineering and Architecture, Anadolu University, Eskişehir, Turkey (e-mail: oarioz@anadolu. edu.tr). amorphous and crystalline elements like quartz, mullite, magnetite and hematite. The presence of silica and alumina lead to usage of fly ash in geopolymers [3].

Geopolymer technology has very low cost and significant contributions to reduce $\mathrm{CO}_{2}$ emissions compared with Ordinary Portland Cement (OPC) Technology [3]. In cement production, about 5-8\% of global $\mathrm{CO}_{2}$ emissions result from decomposition of limestone and combustion of fossil fuels. Concrete made from OPC is the most common product used around the world. In the countries where the population increases rapidly like China and India, concrete industry is expected to grow widely [6].

Geopolymers are new materials comprise of source materials which include high amount of silica and alumina combined with alkaline and silicate solutions [4]. Many materials like kaolinite, metakaolinite, several rocks, fly ash, biomass ash can be used as source materials for geopolimerization. Sodium hydroxide and potassium hydroxide are most common alkaline solutions. The mixture of sodium hydroxide with sodium silicate has been preferred as most effective activator for high strength [7].

The alkaline activation can be defined as a chemical process which specific structures changes rapidly and a new structure becomes partially or totally amorphous. Alkali activation of fly ash is different process from Portland cement but is similar to zeolite synthesis [8].

Geopolymer synthesis can occur at ambient temperature and relatively low temperatures; so it can be called as low energy system [7]-[9]. Starting materials and processing conditions affect the physical and chemical properties of alkali activated systems [10]. Both the curing time and the curing temperature affect the compressive strength [11]. Compressive strength increases with curing temperature. Curing temperature also reduces the time needed for a specific value. Structure of geopolymers are also affected by curing conditions for transition from amorphous to crystalline state [12].

Geopolymerization can be defined as polycondensation process. Aluminate and silicate species originated from raw material react with alkaline activator solution. to form three-dimensional network. [13], [14]. The three-dimensional polymer chain $\mathrm{Si}-\mathrm{O}-\mathrm{Al}-\mathrm{O}$, was proposed by Davidovits in 1978. These structures occur in three types: poly (sialate) (-Si-O-Al-O-), poly (sialate-siloxo) (Si-O-Al-O-Si-O) and poly (sialate-disiloxo) (Si-O-Al-O-Si-O-Si-O). The typical geopolymer composition is generally expressed as $\mathrm{nM}_{2} \mathrm{O} \cdot \mathrm{Al}_{2} \mathrm{O}_{3}-\cdot \mathrm{xSiO}_{2} \cdot \mathrm{yH}_{2} \mathrm{O}$, where $\mathrm{M}$ is an alkali metal [11].

Geopolymers have many mechanical and chemical properties which are equal or even better than OPC Concrete. The advanced properties of geopolymers are quick 
compressive strength development, fire resistance, acid and sulphate resistance and low shrinkage. Most heavy metal ions can be immobilized in geopolymeric structure [2]-[4]. Geopolymer concrete resists up to $1200^{\circ} \mathrm{C}$ with suitable formulations which OPC Concrete explodes at temperatures higher than $300^{\circ} \mathrm{C}[3]$.

Various types of tiles, blocks, panels and sculptors can be produced by geopolymers. Besides technological advantages, geopolymers synthesized with suitable materials can also be used in arts and decoration [3]. The applications of geopolymer materials vary in wide range due to excellent properties [15].

\section{EXPERIMENTAL STUDY}

F class fly ash, techniqual grade sodium hydroxide and sodium silicate solutions were used for geopolymerisation. $4 \mathrm{M} \mathrm{NaOH}$ was prepared as an alkaline solution. Sodium hydroxide was added to sodium silicate and mixed for 15 minutes to get activator solution. Then activator solution poured into fly ash and again mixed until homogenous paste was obtained. Geopolymer paste was cast into steel molds and cured at $120^{\circ} \mathrm{C}$ for 6,15 and 24 hours. Experimental procedure is given in Fig. 1.The authors of the accepted manuscripts will be given a copyright form and the form should accompany your final submission.

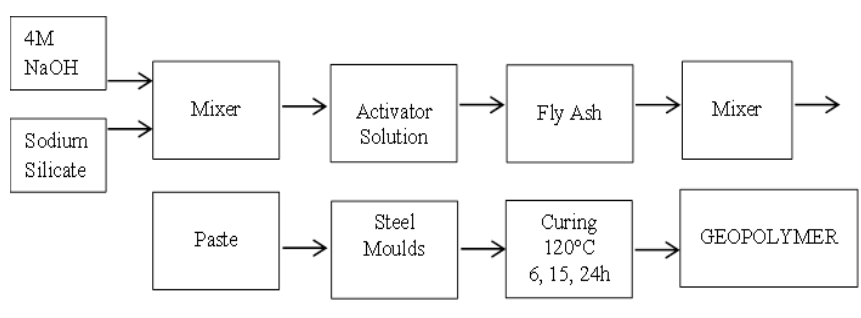

Fig. 1. Flow chart of the experimental study.

After 7 and 28 days aging, compressive strength test was performed on the specimens. To investigate the mineralogical and morphological structure of the geopolymer samples, XRD and SEM techniques were employed to the 28 days aged samples.

\section{RESULTS AND DISCUSSIONS}

The compressive strength values of geopolymeric samples cured at $120^{\circ} \mathrm{C}$ after 7 days aging are given in Table I.

TABLE I: THE COMPRESSIVE STRENGTH VALUES OF GEOPOLYMERIC SAMPLES AGED FOR 7 DAYS

\begin{tabular}{cc}
\hline \hline $\begin{array}{c}\text { Curing Duration } \\
\text { (hour) }\end{array}$ & $\begin{array}{c}\text { Compressive Strength } \\
\text { (MPa) }\end{array}$ \\
\hline 6 & 3,61 \\
15 & 9,69 \\
24 & 10,61 \\
\hline \hline
\end{tabular}

The compressive strength value of the sample cured for 6 hours is low as seen in the table. When the curing duration was increased to 15 hours, the compressive strength was increased nearly 3 times and reached to 9, $69 \mathrm{MPa}$. The increment of the duration to 24 hours did not affect the compressive strength very much. $10,61 \mathrm{MPa}$ was obtained for the sample cured for 24 hours.

Fig. 2 shows the compressive strength values of the geopolymer samples aged for 7 days.

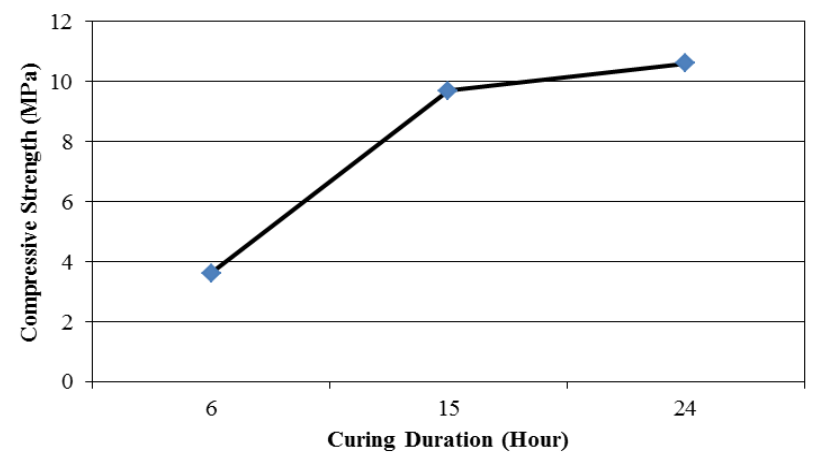

Fig. 2. Compressive strentghs of the geopolymer samples aged for 7 days.

The sharp increase of the compressive strength when the duration was increased from 6 hours to 15 hours can be observed clearly in the Fig.

The compressive strength values of geopolymeric samples cured at $120^{\circ} \mathrm{C}$ after 28 days aging are given in Table II.

TABLE II: THE COMPRESSIVE STRENGTH VALUES OF GEOPOLYMERIC SAMPLES CURED AT $120^{\circ} \mathrm{C}$

\begin{tabular}{cc}
\hline \hline $\begin{array}{c}\text { Curing Duration } \\
\text { (hour) }\end{array}$ & $\begin{array}{c}\text { Compressive Strength } \\
(\mathrm{MPa})\end{array}$ \\
\hline 6 & 7,13 \\
15 & 11,06 \\
24 & 12,53 \\
\hline \hline
\end{tabular}

The minimum compressive strength was obtained at 6 hours $(7,13 \mathrm{MPa})$. The maximum compressive strength was seen when the duration increased from 6 hours to 15 hours (11, $06 \mathrm{MPa})$. The strength increased to $12,53 \mathrm{MPa}$ whenever the curing duration increased to 24 hours. The variations in the strength values are given schematically in Fig. 3.

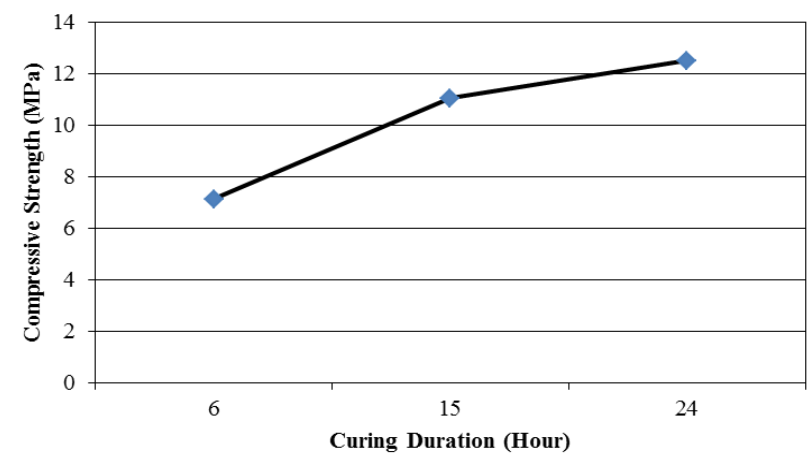

Fig. 3. Compressive strengths of the geopolymer samples aged for 28 days.

As seen in the Fig., the compressive strengths were increased with the curing duration. The increase in the strength values is sharp in the first period. When the duration increased from 15 hours to 24 hours, the compressive strength increased slightly.

Also the effect of aging the geopolymer samples can be determined from the compressive strength results as given in Fig. 4. 


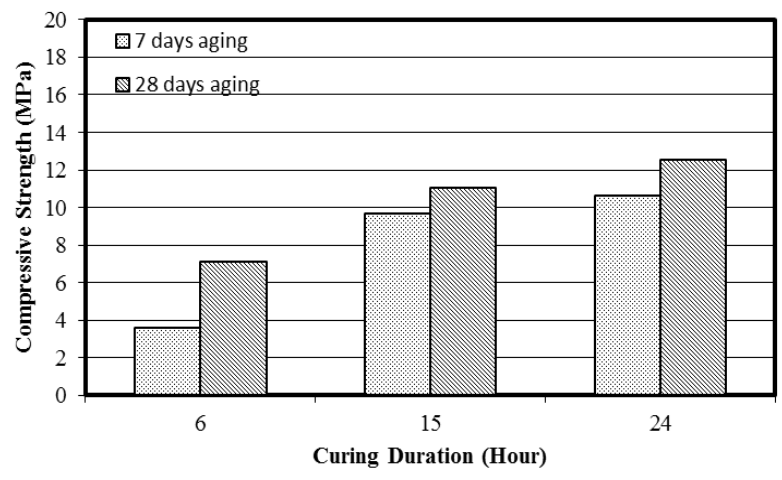

Fig. 4. The effect of aging.

For 6 hours curing duration, the compressive strength was increased significantly with aging. At 7 days the compressive strength was 3,61 $\mathrm{MPa}$, and reached to $7,13 \mathrm{MPa}$ at 28 days aging. Both for 15 hours and 24 hours curing durations, the strengths were increased slightly.

The XRD pattern of the geopolymeric sample cured for 15 hours after 28 days aging is given in Fig. 5. As seen in the Fig., the sample was amorphous and a broad peak between $18-36^{\circ} 2 \ominus$ was observed which is a common characteristic of geopolymers [16], [17].

Fig. 6 shows the XRD pattern of the geopolymeric sample cured for 24 hours The two pattern displayed that the geopolymer sample consisted of quartz and mullite crystals. The curing duration did not change the crystalline structure.

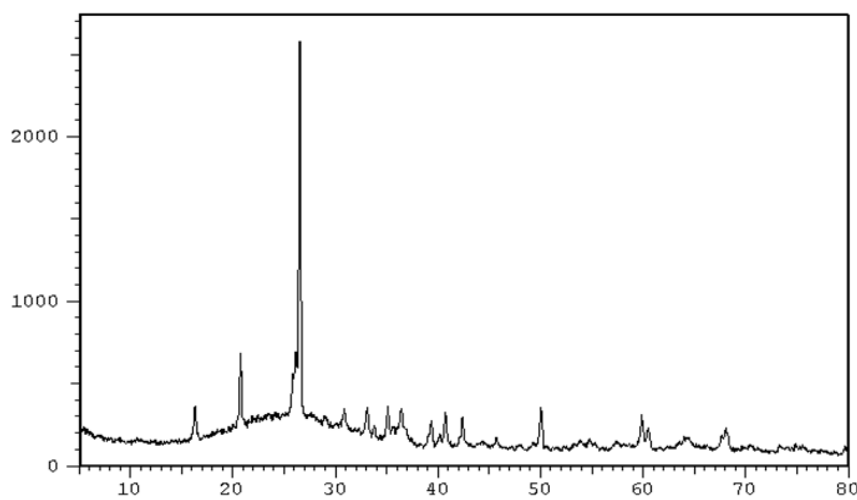

Fig. 5. XRD pattern of the geopolymer sample cured at $120^{\circ} \mathrm{C}$ for 15 hours.

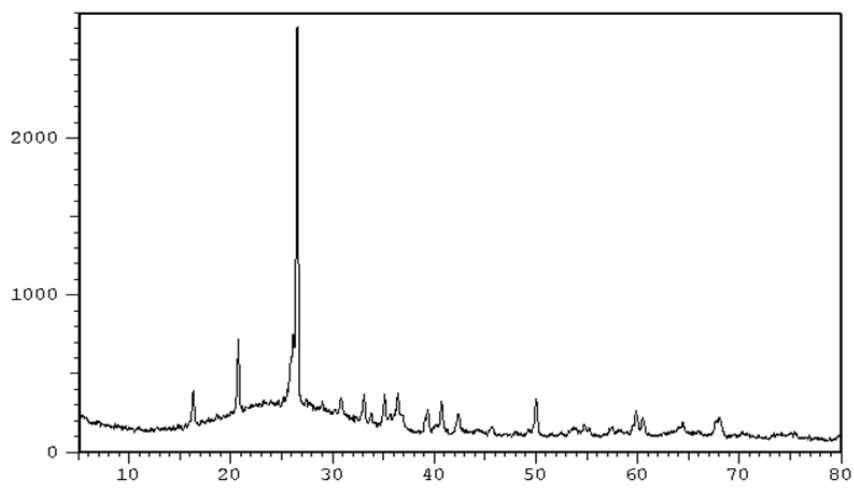

Fig. 6. XRD pattern of the geopolymer sample cured at $120^{\circ} \mathrm{C}$ for 24 hours.

The SEM image of the sample cured for 15 hours is given in Fig. 7. In the micrograph, the geopolymer matrix was not homogenous and unreacted fly ash particles were observed. The needle shaped crystals were also seen in the image of the sample.

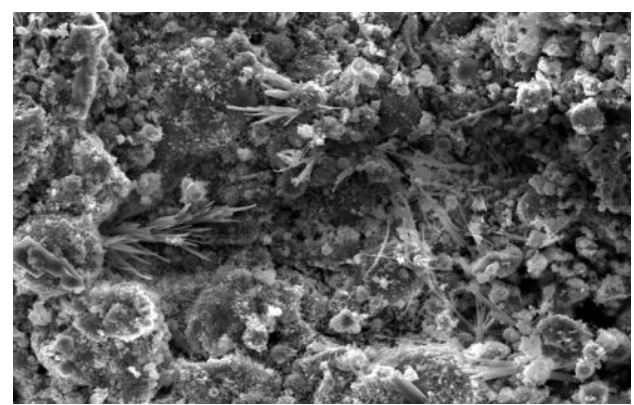

Fig. 7. SEM image of the geopolymer sample cured at $120^{\circ} \mathrm{C}$ for 15 hours.

Fig. 8 shows the SEM image of the sample cured at $120^{\circ} \mathrm{C}$ for 24 hours. The unreacted sodium hydroxide was precipitated in the geopolimeric gel due to evaporation of water at high temperature [15]. The pores were observed beside unreacted fly ash particles and crystals. The needle shaped crystals were also seen as in the geopolymer sample cured for 15 hours.

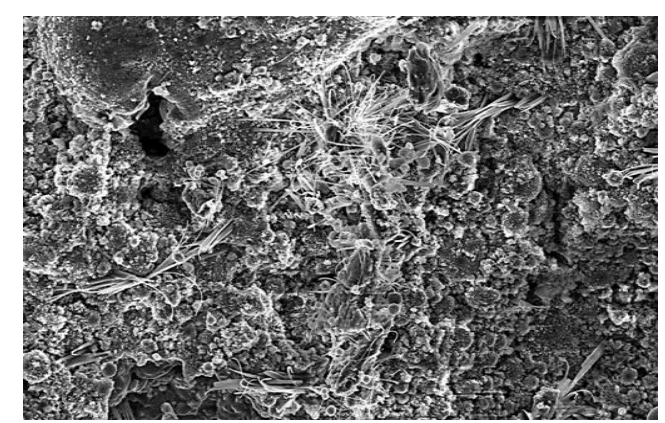

Fig. 8. SEM image of the geopolymer sample cured at $120^{\circ} \mathrm{C}$ for 24 hours.

\section{CONCLUSIONS}

Geopolymers were obtained by using F class fly ash, sodium silicate and sodium hydroxide which has low molarity. The compressive strength values were low as expected because of the low molarity of alkaline solution.

The higher compressive strength values can be obtained with higher molarities if desired for applications like building materials. Also some fillers may be added to increase the compressive strength values.

The compressive strengths increased with increasing curing duration. The increment was much higher when the duration increased from 6 hours to 15 hours. Also aging affected the compressive strengths positively and similar to the effect of curing duration. The strength values increased much higher for the samples cured for 6 hours. The compressive strength increased $97,5 \%$ when aging increased to 28 days for 6 hours curing. The increments were $14,1 \%$ and $18,1 \%$ for 15 hours and 24 hours respectively. These could be caused from geopolymeric reactions.

The geopolymeric reactions might be uncompleted in low curing durations like 6 hours and in early ages. Because of uncompleted reactions, the compressive strengths increased when the durations increased and did not change when the durations prolonged. The reason of the effect of the aging may be similar to the curing duration.

XRD analysis showed that geopolymerisation was achieved according to the amorphous phase and a broad hump. The curing time did not affect the crystal structure of geopolymer samples. 
SEM image showed that all fly ash particles not reacted in the activator solution. It could be due to insufficient molarity or mixing time. The more homogenous gel phase can be achieved with higher molarities of the activator solution. In the SEM images of two samples the precipitation of sodium hydroxide was observed. The precipitation may be prevented when the geopolymer samples cured at the lower temperatures. The high curing temperature caused to the evaporation of water in the geopolymeric gel.

\section{REFERENCES}

[1] M. Ahmaruzzaman, "A review on the utilization of fly ash," Progress in Energy and Combustion Science, vol. 36, pp. 327-363, 2010.

[2] E. A. Ayuso, X. Querol, F. Plana, A. Alastuey, N. Moreno, M. Izquierdo, O. Font, T. Moreno, S. Diez, E. Vazquez, and M. Barra, "Environmental, physical and structural characterisation of geopolymer matrixes synthesised from coal (co-) combustion fly ashes," Journal of Hazardous Materials, vol. 154, pp. 175-183, 2008.

[3] J. Davidovits, "Geopolymer chemistry and applications," Institut Géopolymére, Saint - Quentin, France, ch. 12, pp. 275-279, 2008.

[4] E. I. Diaz, E. N. Allouche, and S. Eklund, "Factors affecting the suitability of fly ash as source material for geopolymers," Fuel, vol. 89, pp. 992-996, 2010.

[5] M. Ahmaruzzaman, "A review on the utilization of fly ash," Progress in Energy and Combustion Science, vol. 36, pp. 327-363, 2010.

[6] J. S. J. V. Deventer, J. L. Provis, P. Duxson, and D. G. Brice, "Chemical research and climate change as drivers in the commercial adoption of alkali activated materials," Waste Biomass Valor, vol. 1, pp. 145-155, 2010.

[7] A. N. Rashad, "A comprehensive overview about the influence of different additives on the properties of alkali-activated slag - A guide for Civil Engineer," Construction and Building Materials, vol. 47, pp. $29-55,2013$

[8] A. M. A. Bakri, H. Kamarudin, M. Bnhussain, I. K. Nizar, A. R. Rafiza, and Y. Zarina, "Microstructure of different $\mathrm{NaOH}$ molarity of fly ash-based green polymeric cement," Journal of Engineering and Technology Research, vol. 3, no. 2, pp. 44-49, 2011.

[9] K. Somna, C. Jaturapitakkul, P. Kajitvichyanukul, and P. Chindaprasirt, "NaOH-activated ground fly ash geopolymer cured at ambient temperature," Fuel, vol. 90, pp. 2118-2124, 2011.

[10] S. Chithiraputhiran, N. Neithalath, S. Chithiraputhiran, and N. Neithalath, "Isothermal reaction kinetics and temperature dependence of alkali," Construction and Building Materials, vol. 45, pp. 233-242, 2013.

[11] G. S. Ryu, Y. B. Lee, K. T. Koh, and Y. S. Chung, "The mechanical properties of fly ash-based geopolymer concrete with alkaline activators," Construction and Building Materials, vol. 47, pp. 409-418, 2013.

[12] M. Criado, A. F. Jimenez, and A. Palomo, "Alkali activation of fly ash. part III: Effect of curing conditions on reaction and its graphical description," Fuel,vol. 89, pp. 3185-3192, 2010.
[13] N. Cristelo, S. Glendinning, L. Fernandes, and T. A. Pinto, "Effect of calcium content on soil stabilisation with alkaline activation," Construction and Building Materials, vol. 29, pp. 167-174, 2012.

[14] J. L. Provis, A. Hajimohammadi, C. A. Rees, and J. S. J. van Deventer, "Analysing and manipulating the nanostructure of geopolymers," in Proc. Nanotechnology in Construction 3-Proceedings of the NICOM3, 2009, pp. 113-128.

[15] S. Andini, R. Cioffi, F. Colangelo, T. Grieco, F. Montagnaro, and L. Santoro, "Coal fly ash as raw material for the manufacture of geopolymer-based products," Waste Management, vol. 28, pp. 416-423, 2008.

[16] P. Duxon, A. F. Jimenez, J. L. Provis, G. C. Lukey, A. Palomo, and J. S. J. van Deventer, "Geopolymer technology: The current state of the art," Journal of Materials Science, vol. 42, pp. 2917-293, 2007.

[17] J. He, J. Zhang, Y. Yu, and G. Zhang, "The strength and microstructure of two geopolymers derived from metakaolin and red mud-fly ash admixture: A comparative study," Construction and Building Materials, vol. 30, pp. 80-91, 2012

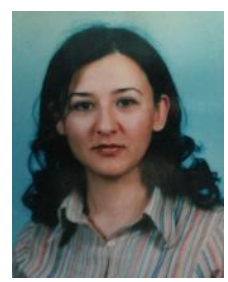

Evren Arioz is working at Department of Chemical Engineering Department in Anadolu University as research and teaching assistant. She took her master degree from Graduate School of Natural and Applied Sciences of Anadolu University. Thesis subject was Pyrolysis of Biomass. She is currently studying and researching about geopolymers in her doctoral studies. She is also making investigations and researches on the subjects Renewable Energy, Pyrolysis and Geopolymers. She is interested in mechanical and microstructural properties of Geopolymers.

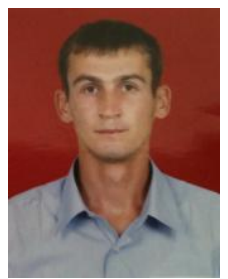

Ömer Arioz is working at Çimbeton, Cimentaş, Cementir Holding as Technical Manager. He took his master degree from Graduate School of Natural and Applied Sciences of Middle East Technical University. Thesis subject was mechanical and physical properties of Fly Ash- FGD Gypsum-Lime based bricks. He took his $\mathrm{PhD}$ degree from Graduate School of Natural and Applied Sciences of Anadolu University. Thesis subject was mechanical and physical properties of concrete. He took his MBA degree from İstanbul Bilgi University. Then, he took his $\mathrm{PhD}$ degree in Economics from Institute of Social Sciences at Anadolu University. He is interested in cement, concrete, management and economics.

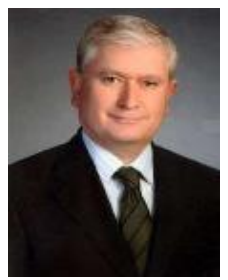

Ö. Mete Kockar is a professor at Department of Chemical Engineering at Anadolu University. He received his master degree in Process Engineering and Reactor Design and doctoral degree in Unit Operations and Thermodynamics at Anadolu University. He received Nato Schoolarship in 1993 and 1994 Tubitak-Nato Schoolarship in 1995. He is interested in Renewable Energy, Pyrolysis, Biomass, Geopolymers. 